\title{
Continuity and change in the relationship between popular music, culture, and technology: An introduction ${ }^{1}$
}

\section{Introduction}

The origins of the relationship between technology and popular music go back as far as the initial formation of popular music itself, and the beginnings of the music industry (Braun 2002; Frith 1986). With the advent of sound recording and reproduction, radio and electricity enabled the transformation of the practices of music production, consumption and sharing in various different ways. The spread of recorded music enabled the sale and distribution of music as a product independent from live performances (Burnett 1992), and related to this, the record label and the "traditional" music business model were born. The traditional record label structure was created and maintained with the aim of selling as many recorded music items as possible. Interpretations of digital technology are characteristically inseparable from the technologically deterministic view that those novelties in certain ways define, direct and shape music, as well as determine its production, distribution and consumption. Naturally, this interpretation is also paradoxical, as however evanescent this angle in deterministic accounts may be, economic and socio-cultural factors are equally important in the diffusion and evolution of technology. All those dilemmas and parallels demonstrate the inseparable and co-evolutionary nature of music and technology, that their development mutually depend on each other. But what patterns and interactions might be unearthed in this relationship, and how does the interaction of music and technology work? Focusing on the relationship between recorded popular music and digital technologies, in this introduction we intend to inspect the following questions: what is the most beneficial way to approach the interaction of music production, distribution, sharing and consumption on the one hand, and technology on the other? How do cultural meanings of audio formats and music technologies change over time and across communities? Finally, how do those cultural meanings coexist with the use of technologies, and how might culture shape technology?

\section{1. 'New' technologies, popular music and society}

So why all the anxiety? The key, in my view, is the currently uneasy relationship of music with technology. In the last 10 years, there has been an explosion in the ways that music can be discovered and consumed driven by technological shifts. Unfortunately, the industry was caught unawares when the digital tide first hit and is only now really acting on the changes it has wrought. But this feels like a paradox because music and technology have traditionally been good bedfellows throughout history. Instruments, records, cassettes, CDs, radio, TV, concert hall amplification are all examples of technologies that have expanded the possibilities for making, discovering and listening to music. (Bolza 2008)

The thoughts of Federico Bolza from 2008, the then senior director of digital development at Sony BMG tell us a lot about the contradictory and uncertain nature of ideas centered around the relationship between music and technology. One of the uncertainties lies with the fluid scope of technology. When we call recent changes and developments in the music world "technological" or of technological origin, then we obviously refer to digital technologies and the internet, the immaterial network as well as the gadgets and tools. Not technology in general, but particular technologies perceived as new. Yet with this notion coexists the universal meaning of technology: technology as the

\footnotetext{
${ }^{1}$ This chapter was supported by the János Bolyai Research Scholarship of the Hungarian Academy of Sciences
} 
sum of all tools and procedures through which music is to be born and represented; the universe of instruments, records, radios, studios, acoustics, amplification and formats.

Interpretations of digital technology, often perceived as new, thus "the" technology (c.f. Taylor 2001: 6-7), are characteristically inseparable from the technologically deterministic view that those novelties in certain ways define, direct and shape music, as well as determine its production, distribution and consumption. Naturally, this interpretation is also paradoxical, as however evanescent this angle in deterministic accounts may be, cultural and social traits are equally important in the diffusion and evolution of technology. The attitude of the late-reacting recording industry might provide an example to this. As it is widely documented, recording industry lobbyists, especially the RIAA (Electronic Frontier Foundation, 2008), initially framed $\mathrm{mp} 3$ and online music sharing as either a fad or a crime (Andersson Schwarz 2014, Leyshon 2001). It thus forced innovations in digital music towards a particular direction, in accordance with the support of the copyright regime's legislative infrastructure backing such - by now partly defunct - technologies as DRM (Digital Rights Management; see McCourt and Burkart 2013).

All these dilemmas and parallels demonstrate the inseparable and co-evolutionary nature of music and technology, that their development mutually depend on each other. But what patterns and interactions might be unearthed in this relationship, and how does the interaction of music and technology work? Focusing on the relationship between recorded popular music and digital technologies, we intend to inspect the following questions: what is the most beneficial way to approach the interaction of music production, distribution, sharing and consumption on the one hand, and technology on the other? How do cultural meanings of audio formats and music technologies change over time and across communities? Finally, how do those cultural meanings coexist with the use of technologies, and how might culture shape technology?

\subsection{A Sides, Radio Edit and YouTube Stars: Changing materialities of music consumption}

As it is represented in the majority of historical works, popular music as we know it today was born as a consequence of a series of changes in the technological ecosystem. The technologically deterministic focus in those narratives (Katz 2004) is not a coincidence. Although music has always been inseparable from instruments and acoustics, at the beginning of the twentieth century three closely related technologies - sound recording, radio and electricity - took the role of "technology" and thus became dominant in the recollections regarding the advent of popular music.

Sound recording and reproduction, radio and electricity enabled the transformation of the practices of music production, consumption and sharing in various different ways. The spread of sound recording and recorded music enabled the sale and distribution of music as a product independent from live performances, and related to this, the record label and the traditional recording-based music business model were born. The traditional record label structure based on the dominance of a small number of so-called major labels was created and maintained with the aim of selling as many recorded music items as possible. The monitoring and scouting of potential new and sellable talents was subordinated to this aim; so was the division of labour between composers, musicians and producers; marketing and PR activities; the creation of sound recording protocols and studio procedures; the established ways of cooperating with partners, contractors and specialists; and the architecture and maintenance of the copyright law regime.

"Video Killed the Radio Star" - the 1979 The Buggles song written by Trevor Horn, Geoff Downes and Bruce Woolley succinctly summarized the widespread assumption according to which by the end of the 1970s the era of the radio had finally come to an end, thanks to the emergence of television technology. A few decades later, in 2010, "Internet Killed the Video Star", performed by The Limousines, reflected a similar mood: internet technology, by the end of the first decade of the new millennium, had killed television and all related cultural formations. The internet as a convergent medium has indeed contributed to the transformation of music-related social practices and of the creative industries in many ways, under the umbrella term of 'digitization' (Allen-Robertson 2013; 2015; Anderson 2014; Bennett-Rogers 2016; Burnett 1993; Hesmondhalgh 2013; Born 2010- 
2015; Spilker 2017). Production of certain styles and genres of music has become more democratized and less location-bound with the proliferation of digital tools and online communication. The boundaries between artists and consumers have also become blurred (Ebare 2004). Besides, with the advent of widely accessible and freely downloadable music, old business models based on the sales of live performance returned after a century dominated by record sales, and new models were also tailored exclusively to online sales. The complexity of the narratives of the relationship between internet and music shows us the extent to which technology's perceived role in music is culturally determined: the period after the appearance of Napster on the turn of the twenty-first century has been evaluated as revolutionary and a time of crisis at the same time (Nowak and Whelan 2014; CarterRogers 2014).

Beyond the parallel existence of conflicting narratives, what role does culture play in the diffusion, interpretation, use and innovation of music technologies and formats? Although it seems attractive to describe the formation of music culture as deterministically defined by technologies, developments of the last century of popular music suggest that the relationship is rather bidirectional, and cultural phenomena are underdetermined by changes in technology - both tools and formats. Technological change is ongoing, and is not altering the culture of popular music necessarily and immediately. As an example, DVD, or later Blu-ray technology could have been used for the storage of music, aside from audiovisual content, but those formats have not become the default means in the distribution of music, nor have they led to the inception of longer albums or tracks. Similarly, album formats and track length shaped by this tradition have not adapted to the infinite storage space available on the internet, although practically music of any length can be stored and made accessible online. Nevertheless, for a while the personal computer was the central music player device at most homes in the western world. Modular or mobile memory cards, sticks or other storage units, however, never became default formats for the music industry. When a band releases an album on a pendrive, for instance, it is usually interpreted as a reflexive, ironic act rather than established practice. Also, it is virtually impossible to find oeuvre collections on HDD drives for sale.

Music television did not kill the radio star, and neither has the internet the music television or the radio star. Besides underdetermination, the parallel existence of technologies is similarly important (Cwynar 2015). In the current music technology ecosystem, vinyl, audio cassettes, CDs and various analog and digital formats, similarly to devices such as turntables, tablets, smartphones and mp3 players - all of which have their own histories (Taylor 2001: 7) -,exist simultaneously. The fact that those tools, technologies and formats - often pictured as representing different stages in technological evolution - do not necessarily terminate other technologies deemed as inferior or less evolved demonstrates that this idea of evolution also underdetermines the use and role of technology in culture.

Simultaneously, usage patterns and functions are subject to change. What was once considered as the essence of life-like sound reproduction (such as records on the turn of the nineteenth and twentieth centuries, see Katz 2004) now might be considered as the representative of warm, analog sound - a modern design piece and collectible item reverbing nostalgic attitudes at the same time. In different eras and for different relevant social groups (Pinch and Bijker 1984) different traits of technologies open to interpretation become important and shape usage. With the diffusion of audio cassettes, a previously less dominant aspect of music listening - portability - became of main importance. The partial relocation from the Hi-Fi-equipped living room to the streets later played an important role in the innovation, marketing and interpretation of subsequently appearing technologies. The CD, the MiniDisc, and later the iPod and the diffusion of all mobile digital players were triggered by a strong market need dominated by the key notion of portability. It is thus hardly possible to define culture-independent technological specifications and evolutionary traces in the history of music technologies and formats (Sterne 2012). What could be attempted instead is to determine what meanings given technologies bear in given social groups and time periods, and how those references change and get in conflict with each other. And, how those conflicting meanings and interpretations shape the use and innovation of technologies. With the help of three theoretical tools - namely cultural meaning, relevant social groups and cultural capital - I aim to interpret the role of a 
number of instances of cultural and value formation in the history of music formats and audio technology formation.

In the 1980s' Hungary, for those who wished to escape from the state ideology and wanted to express themselves, the punk scene, for instance, provided a possibility to do that. For the ruling elite, on the contrary, punk was the threatening, uncontrolled opposition of the underclass. In the interpretative framework of punk, the DIY instruments and low-quality bootleg recordings were considered authentic, while in the eyes of the wider public they were symbols of destruction, amateurism and frugality. Music interpretations, knowledge, traditions, ways of thinking shape cultural meanings attached to technologies, dependent on given social contexts (Strauss and Quinn 1997), which are inseparable from the use and evolution of technologies. All those cultural meanings are constructed in a social environment and form part of the social negotiations and conflicts. Pinch and Bijker (2004) calls those collectivities relevant social groups who favor a particular technological solution or attach a particular cultural meaning to a given technology as opposed to other technologies or meanings. The model of relevant social groups does not necessarily help to precisely describe those collectivities - the aim rather is to trace the process of attaching constructed cultural meanings to technologies.

The clash of relevant social groups interpreting new technologies in radically different ways can be exemplified by the copyright, policy and technology "war" following the advent of peer-to-peer file-sharing technologies. The Recording Industry Association of America (RIAA), as the association representing the stakeholders most dependent on the copyright regime, interpreted the phenomenon as potentially dangerous and made all efforts to eliminate the technology by threatening or suing users. The then blossoming networked "pirate" and free culture movement supporters, on the contrary, understood the technology as the facilitator of creativity and information exchange, also inspired to create a new copyright/left paradigm (Andersson Schwarz-Burkart 2015; FredrikssonArvanitakis 2014). The different attitudes led to different ways in innovation. While on one side the development of closed formats, DRM tools for blocking copying and sharing were on the forefront of strategic thinking, on the other side open source, protocols for hiding online behavior, and sharing platforms were born.

Finally, the notion of cultural capital (Bourdieu 1986; Thornton 1995; Suhr 2012) makes the interpretation of the relationship between cultural meanings and relevant social groups and hierarchies easier, embodying it in a unifying framework. The accumulation of cultural capital strengthens the positions in the social hierarchy, and the ways in which cultural capital can be accumulated is determined by the given sociocultural contexts and local cultural meanings. The accumulation of cultural capital is intertwined at several points with technology in the lives of musical collectivities. In the following I analyze examples of cultural meanings such as values, ethical assumptions, aesthetic judgements and traditions having played important roles in the shaping of the technological ecosystem.

\section{Values, Meanings, Ethics: Cultural Factors in the Formation of Music Technologies}

Several chapters of popular music history show how interests and values attached to certain technologies create situations in which the popular deterministic narrative - according to which music recording technologies evolve from an elementary state towards better-functioning technologies that necessarily eliminate inferior ones - errs (c.f. Taylor 2001; Théberge 2001). One of those chapters is on sound quality. The relationship of sound quality to recorded music is problematic in multiple respects. In some instances sound quality comes as secondary after another trait such as portability. As in the case of the $C D$, audio cassette or various mp3 players, portability has been achieved at the price of sound quality loss. The problem is further complicated by the relativity of "good" quality: the definition of "better" and "worse" sound quality is highly problematic and culture-dependent. What defines good sound quality? Life-likeness, detailedness, or such complicated criteria as the saturation or warmth of the sound? Or simply volume? 
One of the most important examples of the latter aspect overruling all others is the history of loudness wars (Vickers 2010) - an example also illustrative of the relativity of good and bad sound quality. According to a narrow interpretation, loudness wars started with the 1980 s with the diffusion of CD technology. CDs from that era tended to be "louder", meaning that newer records sounded louder than previous ones when played at the same volume control stage. Increasing the volume of the recordings was done during the mastering phase in the studio, mainly with special compressing methods and by "cutting off" some of the details of the recording.

As has been shown by Devine (2013), loudness wars did not begin in the 1980s, rather they had been present at the turn of the nineteenth and twentieth centuries at the beginning of electronic sound amplification. The result - if sound quality is defined by the detailedness, life-likeness and undistortedness of the sound - was serious damage, distortion, radical simplification of the sound in every case. Cultural roots of this phenomenon accompanying the last century of amplification and recorded music point out that according to the masses and huge audiences the perception of better sound was dependent on the perception of higher volume. On jukeboxes, the radio or the Hi-Fi system in the living-room, the record that sounded louder at the same volume control stage was more attractive, thus more sellable. This created constant pressure on the record labels and studios, as well as resentful opposition on the side of audiophiles and critics (Anderson 2007). In this context relevant social groups creating and representing the conflicting cultural meanings of loudness are on the one hand the critics and audiophiles, in whose opinion engineering loudness to this extent is harmful to sound quality; on the other hand, the wider audience and record label studio professionals, in whose interpretation elevating loudness is a valid method for manipulating sound, which results simply in a more attractive sound.

The relationship is further complicated by the diverse and problematic nature of loudness and the complex economic nature of the issue. As fulfilling mass consumer needs was at stake, the goals and expectations were the same in all parts of the backers of the procedure, but cultural meanings of loudness were entirely different in the case of a sound engineer, producer or music listener. Thus the nature of cultural capital that could be accumulated in this interaction is also diverse. The role of an engineer working on a highly successful "loud" album may have appeared attractive or prestigious for the potential customers or for like-minded producers, but definitely not in the eyes of the audiophiles or critics.

In underground punk aesthetics the intentionally low-quality instruments, bootleg recordings and bricolage visual materials were not simply the outcome of the scarcity of resources and results of being outside the major label ecosystem, but products of cultural - aesthetic, ethical - motivations of the scene as a relevant social group. The aesthetic low quality (the damaged, the rasping, the amateur, the noisy, the deformed) from the angle of ideologies of independence and DIY ethics is not simply aesthetically superior but ethically proper practice as well. Producing a record of outstanding sound quality can be interpreted as the violation of the punk ethic and it is possible that taking part in the creation of such a product might result in a decrease of the participants' cultural capital in the community.

Even if in less radical ways, similar patterns can be observed nowadays in the so-called Budapest bedroom pop music scene regarding the relationship between "lo-fi" sound quality, technology use and the ethos of the scene. As Emilia Barna's (2014) paper demonstrates, according to the bedroom pop music performers the (intentionally) low sound quality expresses such values as the distance kept from commercial music production, community values of belonging as opposed to mass production, lack of demand for professionalism, DIY ethics and a lifestyle in general. Similarly, the scene's relationship with technology is as complex as that of the cultural meanings connected to sound quality. Music is born in a bedroom studio, set up in a regular apartment, whose offline material reality provides a safe, comforting space, but the studio, the music and the performers themselves are continuously online. They communicate and compose through the internet, they keep in touch with the scene via the means of social media and they publish their works online. Or, online and in audio cassette format. What cultural reasons can be observed behind this particular choice of technology? 
What kinds of cultural meanings attached to formats are formed in accordance with sound, aesthetics, ethics, lifestyle and identity?

In certain cultural contexts, after the appearance of technologies deemed as new and more developed, certain older technologies thought to be outdated and doomed to death may become interesting and start to flourish again. "Once digital media arrive as 'other', as cyborg sound, the analogue seems to breathe, however rasping the sound" - as Hegarty (2007) puts it in reference to the recent revival of audio cassettes. Thus, with the diffusion of the new technologies almost automatically a nostalgic turn is taken towards the previous, more "humane", "warmer" technologies and sounds. In the last decades this has been demonstrated by the revival of such formats as the audio cassette and vinyl. Usage of the cassette format lives in a particular symbiosis with the nostalgic, offline lo-fi aesthetics and the high-tech online everyday-life practices. The audio cassette could be important because of its "metallic" sound on the one hand, and on the other hand because of personal nostalgic narratives and of the attachment to collectible items (Barna 2014). Also, for the 30-something music listeners in the first decade of the new millennium, the audio cassette brings back the sound of the significant bands of their childhood, for those who were born and raised in the 1980s and were listening to music for the first time most likely the cassette was the first and default medium, and the Walkman the default device (du Gay et al 1997).

The generation nostalgia plays a significant part in bringing back the format and most of the genres closely tied with it through the genres of post-punk, riot grrrl, industrial and noise among others (see Hogan 2010). Closely tied to this trend the lifestyle and feeling of the 1980s underground DIY ethics is being revived in independent label scenes. The studiously outdated, nostalgic technology in turn finds its way to its niche audience through the latest, most state-of-the-art online social platforms.

Besides values of nostalgia, personality, "realness" and opposition, cassette culture emphasizes a particular way of listening to music through the medium. As with a cassette it is virtually impossible to skip to a track (as opposed to vinyl or $\mathrm{mp3}$ ), but one has to reel forward to the next pause on the tape instead, so "the actual tape and the album become one and the same" (Kevin Greenspon in Hogan 2010). This way of listening thus consciously opposes and negates key buzzwords of the current technological ecosystem, namely personalization and immediate access.

As Magaudda (2012) points out, for both practical and symbolic reasons in a number of music scenes the use of vinyl format is fundamental. Most frequently besides digital releases vinyl is the default parallel or secondary release format. Symbolic reasons might be traced back to the domain of design. Limited edition, colored or transparent pieces made unique by multiple solutions are basically intended to make the impression of an artisanal product and as such, they are intended to enter the space of the living-room as collectible items signifying the musical taste of the owner, the collector. Collection of vinyl records as physical objects laces the ethical and aesthetic expectations into a social dimension, in whose creation the whole value chain of the stakeholders involved in the production, distribution and sales and consumption of records takes part .

As presented in Pip Piper's (2012) documentary Last Shop Standing, following the dramatic decline of independent records stores in the UK, record stores formed an alternative universe for music enthusiasts. In that universe owners had a special place, they knew all local music consumers as customers, and they in turn knew the owners personally. Record stores were places not just to buy records but to learn about music and simply just to hang out - they functioned not as mere shops but as institutions, as local social hubs, important sites within scenes or networks of creativity (Leyshon 2001). Despite the decline of record stores and vinyl turning into a niche product from being a mass product, the complex social ethos of record collecting is still present in some (sub)cultures that deem record collecting and using vinyl at DJ performances as an ethically proper practice (Vályi 2010). Those social functions are maintained online, or moving to the digital realm (Baym 2000; 2015; 2018; Bennett-Peterson 2004).

\section{Shelves, Folders, Playlists: Music, Technology and Identity}

What is played on your turntable right now? What kinds of records do you have on your shelves? What kind of music is downloaded to your hard drive? What tracks can be found on your Last.fm playlist? 
What have you listened to recently on Spotify? As music plays a central role in creating and maintaining identities (Born 2011), formats and media of recorded music have been present in the representation of musical taste, thus in the communication of musical identity, and the construction of subjectivities through changing listening practices (Kassabian 2013), from the very beginnings. Who is being represented as authentic in the relevant taste community - in other words, how successfully they accumulate their cultural capital - is dependent partly on how the available musical stocks are stored and displayed.

The appearance and diffusion of new technologies in some cases appear to disrupt the until then conventional relationship of music and collectivities. In some cases the very same traditional conflicts live on, and are reproduced in the gradually transforming technological ecosystem (Bijsterveld-Pinch 2004). The same duality can be observed in the creation of identity communicated by the storage and display of recorded music. The diffusion of the $\mathrm{mp} 3$ format was perceived to disrupt in many respects the community practices linked to the until then dominant carriers. New modes, new tools and practices appeared, but the identity forming and sharing mechanisms represented in the storage of, and listening to, music were constantly reproduced in the changing technological context.

Successful presentation of authenticity in the given technological context partly depends on the success of professionalism and the presentation of being involved. A considerable, well-organized vinyl collection containing a given genre's most important pieces is not about musical educatedness, or literacy - professionalism communicates the time, capital and resources devoted to compiling the collection. Stored music in mp3 format offers different ways in representing authenticity through the communication of devotion and professionalism. As a considerably huge collection does not necessarily signify a considerable investment, and as - due to the immaterial nature of the digital format - cannot function as part of the interior, other aspects become more important. Commitment can rather be communicated by the presentation of the time and resources devoted to putting together a collection of thousands of albums, or hundreds of thousands of tracks and their detailed organizing.

The key moment in both cases is the arrangement and representation of the so-called metadata (Morris 2012). Until the appearance of the CD format, all information related to the music was to be found outside the actual medium - the carrier -, now in the digital world the metadata is often actually the same as the musical content described by it - as in the case of a file-list or, taking a step even further, the act of listening to music itself, as in the case of a playlist or a streamed track on a streaming platform in the cloud (Burkart 2014, Johansson et al 2018). This difference has its own significant importance with regard to the self-representation, identity and subcultural capital accumulated by representation and communication. On the one hand, the circle of the relevant metadata is narrowed down to the data including the name of the performer, the title of the album and the track, or its time length. On the other hand, in cloud-based playlists metadata gains significance not by representing storage data or file organization details but by communicating realtime music consumption behavior. In cloud-based music listening, quantitative aspects of music collecting - whether the collection is vinyl-, cassette- or mp3-based - are hardly possible to evaluate, as in the cloud a virtually infinite amount of music can be accessed any time. Devotion and professionalism, and thus authenticity, are less likely demonstrated by the act of collecting rather than the actual music listening with the proper timing and selection. Interestingly, this way the communicated, represented and actual music listening practices and rites are getting closer to each other, leaving a smaller room for "posing", the practice that allows the questioning of the authenticity. The archiver is replaced by the curator, in a technological ecosystem said to be transforming and new, striving for the old-fashioned respect and recognition, reproducing and recreating the accumulation mechanisms of cultural capital.

\section{Conclusions}

Stories of the inseparable relationship between music technologies, formats and culture, as I aimed to demonstrate through the analyzed examples, are worth being told from a cultural perspective for two 
main reasons. Firstly, because technological specifications tend to underdetermine the patterns of usage, and secondly, even the specifications themselves are inseparable from cultural traits and meanings in the technological ecosystem, as are the processes of innovation. Technological specifications, traits, tools, artifacts and procedures have meanings, and they do not affect societal patterns deterministically. It is not the function that leads their use but usage gives new meanings to the ever-changing functions: the cultural construction of technology - involving the negotiation and conflicts of relevant social groups and the accumulation of cultural capital - continuously goes on.

\section{References}

Allen-Robertson J (2013) Digital culture industry: A history of digital distribution. Palgrave MacMillan.

Allen-Robertson J (2015) The materiality of digital media: The hard disk drive, phonograph, magnetic tape and optical media in technical close-up. New Media \& Society, Vol 19, Issue 3, pp. $455-470$.

Anderson Ch (2006) The Long Tail. Hyperion.

Anderson T (2007) How CDs are remastering the art of noise. The Guardian, 18 January. Available online at: http://www.theguardian.com/technology/2007/ian/18/pop.music

Anderson T J (2014) Popular Music in a Digital Music Economy. New York: Routledge.

Andersson Schwarz J (2014) Online File Sharing: Innovations in Media Consumption. Routledge.

Andersson Schwarz J \& Burkart P (2015) Piracy and Social Change. Popular Communication, 13:1, 1-5.

Barna E (2017) "The perfect guide in a crowded musical landscape": Online music platforms and curatorship. First Monday, Volume 22, Number 4 - 3 April. Available online at:

http://firstmonday.org/ojs/index.php/fm/article/view/6914/6086

doi: http://dx.doi.org/10.5210/fm.v22i14.6914

Barna E (2014) A hálószoba, a stúdió és a közösségi média találkozása. A budapesti hálószobapop-színtér. Információs Társadalom 2014(4): 30-45.

Baym NK (2018) Playing to the Crowd: Musicians, Audiences, and the Intimate Work of Connection. New York University Press.

Baym NK (2015) Personal Connections in the Digital Age, Second Edition. Polity Press.

Baym NK (2000) Tune In, Log On: Soaps, Fandom, and Online Community. Sage.

Bennett A \& Peterson RA (2004)eds Music Scenes: Local, Translocal, and Virtual. Vanderbilt University Press.

Bennett A \& Rogers I (2016) Popular Music and Materiality: Memorabilia and Memory Traces. Popular Music and Society, Vol 39, Issue 1 Pages 28-42.

Bijsterveld K \& Pinch T (2004)eds. Special Issue: Sound Studies: New Technologies and Music. Social Studies of Science 34 (October): 634-817.

Bolza F (2008) Music and technology: Friends reunited. Telegraph, 11 August. Available online at: http://blogs.telegraph.co.uk/technology/shanerichmond/4872757/Music and technology Friends reunited/

Born G (2010-2015) Music, Digitisation, Mediation: Towards Interdisciplinary Music Studies Project. ERC, Oxford University. 
Born G (2011) Music and the materialization of identities. Journal of Material Culture, Vol 16, Issue 4, pp. 376388.

Bourdieu P (1986) The forms of capital. In: Richardson J (ed) Handbook of Theory and Research for the Sociology of Education. New York: Greenwood, 241-258.

Braun H-J (2002)ed. Music and Technology in the Twentieth Century. Baltimore: Johns Hopkins University Press.

Burkart P (2014) Music in the Cloud and the Digital Sublime. Popular Music and Society, Vol 37. Issue 4, 393407.

Burnett R (1992) The implications of ownership changes on concentration and diversity in the phonogram industry. Communication Research, Vol 19, Issue 6, pp. 749-769.

Burnett R (1993) The popular music industry in transition. Popular Music and Society, 17:1, 87-114.

Carter D \& Rogers I (2014) “Fifteen years of 'Utopia': Napster and Pitchfork as technologies of democratization," First Monday, volume 19, number 10. Available online at: http://firstmonday.org/article/view/5543/4122, doi: http://dx.doi.org/10.5210/fm.v19i10.5543.

Collins, S and S Young 2014. Beyond 2.0: The future of music. Sheffield: Equinox.

Cwynar C (2015) More than a "VCR for radio": The CBC, the Radio 3 podcast, and the uses of an emerging medium. Journal of Radio \& Audio Media, 17, 82-95.

Devine K (2013) Imperfect sound forever: loudness wars, listening formations and the history of sound reproduction. Popular Music, 32(2): 159-176.

du Gay P, Hall S, Jones L, Mackay H \& Negus K (1997) Doing Cultural Studies: The Story of the Sony Walkman. London: Sage.

Ebare S (2004) Digital music and subculture: Sharing files, sharing styles. First Monday 9(2). Available online at: http://firstmonday.org/issues/issue9_2/ebare/index.html

Electronic Frontier Foundation. (2008) RIAA v. The People: Five Years Later. Available online at: https://www.eff.org/wp/riaa-v-people-five-years-later

Fredriksson M \& Arvanitakis J (2014)eds. Piracy: Leakages from Modernity. Litwin Books.

Frith S (1986) Art versus Technology: The Strange Case of Popular Music. Media, Culture and Society, 8.3: 263279.

Hegarty P (2007) The Hallucinatory Life of Tape. Culture Machine, Vol 7. Available online:

http://culturemachine.net/index.php/cm/article/view/82/67

Hesmondhalgh D (2013) The Cultural Industries. $3^{\text {rd }}$ edition. Sage.

Hogan M (2010) This is not a mixtape. Pitchfork, 22 February. Available online:

http://pitchfork.com/features/articles/7764-this-is-not-a-mixtape/

Johansson S, Werner A, Åker P \& Goldenzwaig G (2018) Streaming Music. London: Routledge.

Jansson, J \& B Hracs (2018) Conceptualizing curation in the age of abundance: The case of recorded music.

Environment and Planning A: Economy and Space, June 21

https://doi.org/10.1177/0308518X18777497. 
Kassabian A (2013) Ubiquitous Listening. Affect, Attention, and Distributed Subjectivity. University of California Press.

Katz M (2004) Capturing Sound. How Technology Has Changed Music. Berkeley and Los Angeles, California: University of California Press.

Lee M (2013) The 360 deal and the 'new' music industry. European Journal of Cultural Studies, Vol 16, Issue 1, pp. 77 - 99.

Leyshon A, Webb P, French S, Thrift N \& Crewe L (2005) On the reproduction of the musical economy after the Internet. Media, Culture \& Society, Vol 27, Issue 2, pp. $177-209$.

Leyshon A (2001) Time-Space (and Digital) Compression: Software Formats, Musical Networks, and the Reorganisation of the Music Industry. Environment and Planning A: Economy and Space, 33 (1) pp. 49-77.

Magaudda P (2011) When materiality 'bites back': Digital music consumption practices in the age of dematerialization. Journal of Consumer Culture, 11(1): 15-36.

Mazierska E, Gillon L \& Rigg T (2018)eds. Popular Music in the Post-Digital Age: Politics, Economy, Culture and Technology. Bloomsbury Academic.

McCourt T \& Burkart P (2003) When Creators, Corporations and Consumers Collide: Napster and the Development of On-line Music Distribution. Media, Culture \& Society, Vol 25, Issue 3, pp. 333 - 350. https://doi.org/10.1177/0163443703025003003

Morris JW (2012) Making music behave: Metadata and the digital music commodity. New Media \& Society, 14(5): 850-866.

Morris, Jeremy Wade \& Devon Powers (2015) Control, curation and musical experience in streaming music services. Creative Industries Journal, 106-122

Morton D (1998-2006) Recording History: the history of recording technology. Available online at: http://www.recording-history.org/

Mulligan, M. 2014. "The death of the long tail: The superstar music economy," Music Industry Blog (4 March), at https://musicindustryblog.wordpress.com/2014/03/04/the-death-of-the-long-tail/, accessed 17 August 2016.

Nick P (2018) Popular Music, Digital Technology and Society. Sage.

Nowak R \& Whelan A (2014) Editorial: On the 15-year anniversary of Napster-Digital music as boundary object. First Monday 19(10) Available online at: http://firstmonday.org/ojs/index.php/fm/article/view/5542/4121

Pinch T J \& Bijker W (1984) The Social Construction of Facts and Artifacts. In: Johnson DG \& Wetmore JM (eds) Technology and Society. Building Our Sociotechnical Future. Cambridge, MA: MIT Press, 107-140.

Pinch T, \& Bijsterveld K (2003) Should one applaud? Breaches and boundaries in the reception of new technology in music. Technology and Culture, 44(3).536-559.

Piper P (2012) Last Shop Standing. Documentary. UK: Blue Hippo Media.

Reynolds S (2010) Retromania: Pop Culture's Addiction to Its Own Past. Farrar, Straus and Giroux: New York.

Spilker H S (2017) Digital Music Distribution: The Sociology of Online Music Streams. Routledge.

Stahl G (2004) „'It's like Canada Reduced': Setting the Scene in Montreal.” In A Bennett és K Kahn-Harris (eds) After Subculture: Critical Studies in Contemporary Youth Culture. Basingstoke: Palgrave Macmillan, 51-64 
Sterne J (2012) MP3: The meaning of a format. Durham, NC: Duke University Press.

Strauss C \& Quinn N (1997) A Cognitive Theory of Cultural Meaning. Cambridge, UK: Cambridge University Press.

Straw W (1991) Systems of articulation, logics of change: Communities and scenes in popular music. Cultural Studies, 5:3, 368-388.

Straw W (2001) „Scenes and Sensibilities.” Public 22/23: 245-257

Suhr H C (2012) Social Media and Music: The Digital Field of Cultural Production. New York: Peter Lang.

Taylor T D (2001) Strange Sounds: Music, Technology and Culture. New York: Routledge.

Théberge P (2001) ‘Plugged in': Technology and popular music. In Frith S, Straw W, \& Street J (eds) The Cambridge Companion to Pop and Rock (Cambridge Companions to Music) pp. 1-25). Cambridge: Cambridge University Press.

Thornton S (1995) Club Cultures: Music, Media and Subcultural Capital. Cambridge: Polity Press.

Tofalvy T (2014) 'MySpace bands' and 'tagging wars' Conflicts of genre, work ethic and media platforms in an extreme music scene. First Monday, Volume 19, Number 9 - 1 September. Available online at: http://firstmonday.org/ojs/index.php/fm/article/view/4354/4115

Tschmuck P (2016) From record selling to cultural entrepreneurship: The music economy in the digital paradigm shift. In Wikström P \& DeFillippi R (2016) Business Innovation and Disruption in the Music Industry. Cheltenham: Edward Elgar Publishing.

Valyi G (2010) Digging in the crates: Practices of identity and belonging in a translocal record collecting scene. Unpublished doctoral thesis, Goldsmith College, University of London, London.

Vickers E (2010) The Loudness War: Background, Speculation and Recommendations. Audio Engineering Society, 129th Convention, San Francisco, CA, USA, November 4-7. Available online at: http://www.sfxmachine.com/docs/loudnesswar/loudness war.pdf

Vonderau P (2015) The Politics of Content Aggregation. Television \& New Media, Vol 16, Issue 8, pp. 717 - 733. 